\title{
A comparison of ice water content measurement techniques on the FAAM BAe-146 aircraft
}

\author{
S. J. Abel, R. J. Cotton, P. A. Barrett, and A. K. Vance \\ Met Office, Exeter, UK \\ Correspondence to: S. J. Abel (steven.abel@metoffice.gov.uk)
}

Received: 25 March 2014 - Published in Atmos. Meas. Tech. Discuss.: 14 May 2014

Revised: 25 July 2014 - Accepted: 1 August 2014 - Published: 17 September 2014

\begin{abstract}
This paper presents a comparison of ice water content $\left(q_{\mathrm{i}}\right)$ data from a variety of measurement techniques on the Facility for Airborne Atmospheric Measurements (FAAM) BAe-146 research aircraft. Data are presented from a range of cloud types measured during the PIKNMIX field experiment that include mixed-phase stratocumulus, cumulus congestus and cirrus clouds. These measurements cover a broad range of conditions in which atmospheric ice particles are found in nature, such as the low-ice-water-content environments typically found in midlatitude cirrus and the environments with much higher ice water content often observed in cold convective clouds. The techniques include bulk measurements from (i) a Nevzorov hot-wire probe, (ii) the difference between the measured total water content (condensed plus vapour) and the water vapour content of the atmosphere and (iii) a counterflow virtual impactor (CVI) (only for cirrus measurements). We also estimate the $q_{\mathrm{i}}$ from integration of the measured particle size distribution (PSD) with assumptions on how the density of ice particles varies as a function of size.

The results show that the only bulk ice water content technique capable of measuring high $q_{\mathrm{i}}$ values (several $\mathrm{g} \mathrm{m}^{-3}$ ) was the method of total water content minus water vapour. For low ice water contents we develop a new parametrisation of the Nevzorov baseline drift that enables the probe to be sensitive to $q_{\mathrm{i}} \pm 0.002 \mathrm{~g} \mathrm{~m}^{-3}$. In cirrus clouds the agreement between the Nevzorov and other bulk measurements was typically better than a factor of 2 for the CVI $\left(q_{\mathrm{i}}>\right.$ $\left.0.008 \mathrm{~g} \mathrm{~m}^{-3}\right)$ and the method of total water content minus water vapour $\left(q_{\mathrm{i}}>0.02 \mathrm{~g} \mathrm{~m}^{-3}\right)$. Good agreement with the bulk measurements for all cases could be obtained with the estimate from the PSD provided that appropriate a priori assumptions on the mass-dimension relationship were made.
\end{abstract}

This is problematic in the convective clouds sampled because pristine ice particles, heavily rimed particles and supercooled liquid drops were all present. In a cirrus case, we show that using a temperature-dependent mass-dimension relation was required to match the bulk measurement of $q_{\mathrm{i}}$.

\section{Introduction}

Clouds exert large impacts on the radiative, thermodynamic and dynamic processes of the atmosphere. They also play a key role in the hydrological cycle of the earth-atmosphere system. Including a realistic representation of the microphysical processes that drive the evolution of clouds and precipitation in numerical weather prediction and climate models is therefore required. The bulk microphysical schemes that are typically employed in such models use the ice water content as a prognostic variable, from which other cloud microphysical process rates such as the aggregation and fall speed of ice particles are derived. Errors in the model ice water content can, therefore, propagate into all aspects of a model's cloud parametrisation scheme. Airborne measurements of cloud ice water content are a key tool for assessing the fidelity of model predictions and for developing improvements to the cloud parametrisation schemes themselves.

A variety of techniques exist to measure ice water content on airborne platforms, e.g. Davis et al. (2007), Baumgardner et al. (2011) and Korolev et al. (2013a). These include the following: (i) techniques whereby ice particles are evaporated in an inlet and the subsequent enhancement to the water vapour content is measured, (ii) methods that relate the power supplied to melt and evaporate ice particles impacting on a hot-wire sensor to the bulk ice water content and 
(iii) integration of the measured ice particle size distribution. The latter method requires an assumption of how the ice particle density varies as a function of particle size. The Facility for Airborne Atmospheric Measurements (FAAM) BAe146 research aircraft (http://www.faam.ac.uk) has a comprehensive suite of instruments for making cloud microphysics measurements including the aforementioned ice water content techniques.

The objective of this paper is to give an overview of the ice water content measurement capability on the FAAM BAe-146 aircraft and to compare the different techniques across a wide range of cloud regimes, including mixed-phase boundary layer stratocumulus, high-ice-water-content environments in cumulus congestus and lower-ice-water-content environments associated with cirrus clouds. Section 2 gives a description of the different methods. Section 3 presents a comparison of the ice water content data from a variety of research flights undertaken during the PIKNMIX field campaign. Section 4 then gives an overview of the performance of the different ice water content measurements.

\section{Measurement techniques}

We begin by introducing some terminology that will be used throughout the manuscript, followed by an overview of the various ice water content measurement techniques. The total water content of an air parcel $\left(q_{\mathrm{t}}\right)$ is given by

$$
\begin{aligned}
q_{\mathrm{t}} & =q_{\mathrm{v}}+q_{1}+q_{\mathrm{i}} \\
& =q_{\mathrm{v}}+q_{\mathrm{c}},
\end{aligned}
$$

where the subscripts $\mathrm{v}, 1$ and i refer to the vapour, liquid and ice phases. The subscript $\mathrm{c}$ refers to the total condensedwater content, which is the sum of the liquid and ice water contents.

\subsection{Nevzorov hot-wire probe}

The Sky Phys Tech Inc. hot-wire Nevzorov probe (Korolev et al., 1998, 2013a) consists of separate sensors to measure the bulk total condensed-water content $\left(q_{\mathrm{c}}\right)$ and the liquid water content $\left(q_{1}\right)$. The $q_{\mathrm{c}}$ sensor consists of a heated cone mounted on a vane which orients the cone opening directly into the airflow. The electrically heated cone is held at a constant temperature, sufficient to melt and evaporate liquid and ice particles captured in the cone. The cone is the newer, modified deep cone which has an opening of $8 \mathrm{~mm}$ diameter and an opening angle of $60^{\circ}$. The deep-cone version has been shown to have an improved collection efficiency compared to the original shallow-cone version which had an opening angle of $120^{\circ}$ (Korolev et al., 2013a). The $q_{1}$ sensor consists of a heated wire wound onto a copper rod which is fixed to the leading edge of the vane $(1.8 \mathrm{~mm}$ in diameter by $16 \mathrm{~mm}$ in length). Liquid droplets impacting either the $q_{\mathrm{c}}$ or the $q_{1}$ sensors should form a thin surface film and evaporate fully.
Ice particles, however, tend to break up and fall away from the convex surface of the $q_{1}$ sensor, although a residual signal from these ice particles is often observed (Korolev et al., 1998). In this study we use the data from the $q_{1}$ sensor to solely identify regions of liquid water.

The bulk water content from the sensors is calculated directly from the extra electrical energy supplied that is required for the melting and evaporating processes. As the heated sensors are exposed to the airflow, forced convective cooling due to the airflow over the sensor adds to the power requirement to melt and evaporate cloud particles. The forced convective cooling depends on the aircraft attitude and environmental conditions. A reference sensor, aerodynamically shielded from cloud particles, partially compensates for this convective cooling and enables the removal of the dry-air heat-loss term. The lack of full compensation leads to a "baseline drift" observed on the $q_{\mathrm{c}}$ sensor during the period of a flight. Korolev et al. (1998) showed the effect of airspeed, temperature and pressure on the baseline drift and that, in straight and level flight when the environmental conditions are largely invariant, the probe sensitivity was $\pm 0.002 \mathrm{~g} \mathrm{~m}^{-3}$. During a full flight on the National Research Council Convair-580 aircraft, they estimated that the baseline drift of the probe was more typically about $0.035 \mathrm{~g} \mathrm{~m}^{-3}$. In Appendix A, we show how the $q_{\mathrm{c}}$ baseline drift of the sensor on the FAAM BAe-146 aircraft can be parametrised as a function of environmental variables and that even on a nonstraight and non-level flight, the probe sensitivity can reach $\pm 0.002 \mathrm{~g} \mathrm{~m}^{-3}$.

\subsection{Total water probe and WVSS-II}

The total water probe is fully described by Nicholls et al. (1990). Ambient air containing cloud particles enters an isokinetic inlet. The cloud particles are then evaporated through heating and mechanical break-up before the resulting water vapour content of the air is measured using a fast response Lyman- $\alpha$ absorption hygrometer. As the cloud particles are fully evaporated by the time they reach the hygrometer, this equates to a direct measurement of $q_{\mathrm{t}}$. The total water probe is typically set up to measure $q_{\mathrm{t}}$ in a dynamic range of 0 to $20 \mathrm{~g} \mathrm{~kg}^{-1}$, although this is adjustable by altering the physical gap between the source and detector tubes of the hygrometer (Nicholls et al., 1990). In the absence of any condensed water in the ambient air, i.e. in clear-air conditions, the total water probe provides a measurement of $q_{\mathrm{v}}$. The instrument needs to be calibrated against a reference $q_{\mathrm{v}}$ measurement in cloud-free conditions because the magnesium fluoride windows on the Lyman- $\alpha$ hygrometer degrade during a flight due to etching on the surface of the windows by contaminants in the air in the presence of UV.

In this study, we calibrate the total water probe against a reference SpectraSensors Water Vapor Sensing Systems version-2 (WVSS-II) near-infrared tunable diode laser 
absorption hygrometer (see Appendix B for details). The residual difference in clear air between the two instruments post calibration varies on a flight-by-flight basis but is typically between 0.01 and $0.03 \mathrm{~g} \mathrm{~m}^{-3}$. There are two WVSS-II instruments fitted on the FAAM BAe-146 aircraft. One has a standard flush inlet and the other a modified Rosemount inlet that is mounted on a short pylon so that the inlet is outside of the aircraft boundary layer (Vance et al., 2014). Vance et al. (2014) document the performance of the two WVSS-II instruments over a large number of flights, finding that, in cloud-free conditions, the WVSS-II fed from the Rosemount inlet is typically in good agreement with a Buck CR2 chilled mirror hygrometer (annually calibrated at the National Physical Laboratory, Teddington) in the range $0.1<q_{\mathrm{v}}<4 \mathrm{~g} \mathrm{~m}^{-3}$ $(1 \sigma=6 \%)$. The Rosemount and flush-fed WVSS-II agree in moist conditions $\left(1 \sigma=2 \%\right.$ at $\left.2 \mathrm{~g} \mathrm{~m}^{-3}\right)$, but the flush-fed WVSS-II overreads to progressively greater extents in drier conditions. We therefore utilise the Rosemount WVSS-II for cirrus cloud measurements where the $q_{\mathrm{v}}$ can be low enough for significant biases to exist in the $q_{\mathrm{v}}$ measured by the flushfed WVSS-II. However, Vance et al. (2014) also show that the Rosemount-fed WVSS-II can be subject to a high bias in the presence of liquid water cloud due to the evaporation of cloud drops in the inlet (example also shown in Fig. 1), and we therefore use the flush-mounted inlet for the flights in mixed-phase conditions in this study.

The bulk $q_{\mathrm{c}}$ is then simply calculated as the $q_{\mathrm{t}}$ from the total water probe minus the $q_{\mathrm{v}}$ from the WVSS-II, hereafter referred to as the TWP-minus-WVSS-II method. This is similar to the method used in Brown and Francis (1995) but has the advantage of using the same reference $q_{\mathrm{v}}$ measurement for calibrating the total water probe and for providing the incloud measurement of $q_{\mathrm{v}}$.

\subsection{Counterflow Virtual Impactor}

A counterflow virtual impactor (CVI) inlet is used to select cloud particles with a larger aerodynamic diameter than the cut size, $D_{50} . D_{50}$ is the diameter at which the collection efficiency of the particles is $50 \%$. These cloud particles are evaporated into a particle-free dry air stream and the resultant water vapour concentration within the system is measured using a dual-channel Lyman- $\alpha$ hygrometer. The CVI inlet and Lyman- $\alpha$ Hygrometer system is very similar to that used by Noone et al. (1993) to sample cirrus clouds. This CVI has a blunt-tip geometry with the outer diameter of the tip being $11 \mathrm{~mm}$ and the diameter of the inlet $3 \mathrm{~mm}$. The inlet and hygrometer used in this experiment have previously been flown on a different aircraft and have successfully measured the properties of boundary layer liquid clouds (Öström et al., 2000). On the FAAM BAe-146 the inlet is mounted on the starboard side of the aircraft, close to the fuselage centreline below the seventh window. The probe arm is angled down so that the inlet is close to isoaxial when in level flight in the planetary boundary layer. The small departures from isoaxial sampling at higher altitude (of the order of $1-2^{\circ}$ ) do not appear to significantly affect the data presented in this work.

Particle stop distances (e.g. Laucks and Twohy, 1998) for unit density liquid spheres, accounting for local air density, result in a calculated cut size range for this inlet of $4 \mu \mathrm{m} \leq D_{50} \leq 7 \mu \mathrm{m}$. The CVI tip did not have anti-icing heaters fitted during the PIKNMIX campaign, and so sampling was not possible in the presence of supercooled liquid. For this study, the measurements are restricted to periods when the aircraft is sampling cirrus clouds. The blunt tip may result in a less sharp cut function. This limitation and the implications of the cut size are discussed in Appendix C.

Water vapour from evaporated cloud particles is measured within the CVI using a dual-path Lyman- $\alpha$ hygrometer (Zuber and Witt, 1987) similar to that used by Ström et al. (1994). Having a reference channel in addition to the sample channel avoids the need for absolute calibration of the hygrometer as the humidity within the instrument can be determined from first principles. The range of $q_{\mathrm{c}}$ that can be measured by the CVI for the flights presented here is altitude dependent and is $0.015 \leq q_{\mathrm{c}} \leq 0.2 \mathrm{~g} \mathrm{~m}^{-3}$ at $2 \mathrm{~km}$ and $0.005 \leq q_{\mathrm{c}} \leq 0.04 \mathrm{~g} \mathrm{~m}^{-3}$ at $8 \mathrm{~km}$. The dual-channel configuration minimises the impact of variable lamp output but the Lyman- $\alpha$ hygrometer performance is still expected to drift over time, so a baseline removal procedure is required. The baselining procedure involves regular zero-checks throughout a flight. During a zero-check, dry air is directed into both channels of the hygrometer, and the ratio ("dry ratio") between detectors is measured. The procedure to determine the dry ratio and subsequent calculation of $q_{\mathrm{c}}$ is described in detail in Appendix C.

\subsection{Integration of the particle size distribution}

Whilst not a bulk measure of the ice water content, integration of the measured particle size distribution (PSD) can be used to provide an estimate of $q_{\mathrm{i}}$. This requires an implicit assumption of how the particle density varies as a function of particle size. This is typically characterized using a massdimension $(M-D)$ relation that takes the generalized form $M=a D^{b}$, where $a$ and $b$ are constants. There are a wealth of such $M-D$ relations in the literature that have been derived from both observational data sets and from theoretical studies. These studies show that the parameters $a$ and $b$ can vary substantially depending on the environmental conditions and particle habit. For example, Mitchell et al. (1990) presented $M-D$ relations specific to various ice-crystal habits, showing values of $b$ ranging from 1.8 (needles and long columns) to 2.6 (short columns and plates). One therefore has to have an a priori knowledge of the characteristic particle habit that is measured in order to choose an appropriate relation.

In this study we will show examples of the $q_{\mathrm{i}}$ calculated from the integration of the measured PSD using $M-D$ relations that have been derived from data sets that represent pristine ice particles and aggregates thereof (Baran et al., 2011; 
Table 1. $M=a D^{b}$ relations used in this study. Those in italic font are representative of pristine ice particles or aggregates. The bold font is representative of more heavily rimed particles. Two temperature-dependent relations from this study (cirrus flight B672) are also included, where the constants are $C_{0}=0.0901, C_{1}=0.001449, C_{2}=1.9868$ and $C_{3}=-0.004059$. The unit of temperature, $T$, is ${ }^{\circ} \mathrm{C}$. $\rho_{0}$ is a fixed upper limit on the value of the particle density.

\begin{tabular}{lllll}
\hline$M-D$ relation & $a$ & $b$ & $\rho_{0}\left(\mathrm{~kg} \mathrm{~m}^{-3}\right)$ & Validity \\
\hline Baran et al. (2011) & 0.04 & 2.0 & 920 & \\
Brown and Francis (1995) & 0.0185 & 1.9 & 920 & \\
Cotton et al. (2013) & 0.0257 & 2.0 & 700 & \\
Heymsfield et al. (2010) & 0.176 & 2.2 & 920 & \\
Mitchell et al. (2010) & 35.13 & 2.814 & 920 & $D \leq 240 \mu m$ \\
& 0.00764 & 1.805 & - & $D>240 \mu m$ \\
\hline This study (flight B672) & $C_{0}+C_{1} T$ & 2.1 & 920 & $-48<T<-16^{\circ} \mathrm{C}$ \\
& 0.0669 & 2.1 & 920 & $T \geq-16{ }^{\circ} \mathrm{C}$ \\
This study (flight B672) & 0.05 & $C_{2}+C_{3} T$ & 920 & $-48<T<-16^{\circ} \mathrm{C}$ \\
& 0.05 & 2.05 & 920 & $T \geq-16^{\circ} \mathrm{C}$ \\
\hline Heymsfield and Kajikawa (1987) & $\mathbf{1 6 9 . 5 9 3}$ & $\mathbf{3 . 1}$ & - & \\
\hline
\end{tabular}

Brown and Francis, 1995; Cotton et al., 2013; Heymsfield et al., 2010; Mitchell et al., 2010). We will contrast these with an $M-D$ relation that is more representative of heavily rimed graupel particles (R4b lump graupel in Heymsfield and Kajikawa (1987)) and use the different relations to illustrate the uncertainties involved in estimating $q_{\mathrm{i}}$ from the measured PSD. When presenting example data in Sect. 3, we will refer to these $q_{\mathrm{i}}$ estimates from the integration of the PSD as either using the ice $M-D$ relations (italic font in Table 1) or the graupel $M-D$ relation (bold font in Table 1).

A variety of optical particle counters (OPC) and optical array probes (OAP) mounted on under-wing pylons on the FAAM BAe-146 aircraft are used to characterise the PSD over a particle diameter range of $2 \mu \mathrm{m}$ to $6.2 \mathrm{~mm}$. The OPCs used include a Cloud Droplet Probe (CDP) and a Small Ice Detector Mark-2 (SID-2). For conditions dominated by liquid water droplets, we assume that the particles measured by the OPCs are spherical. For cases dominated by ice particles, we assume that the particles are quasi-spherical and modify the CDP and SID-2 PSD as in Cotton et al. (2013). The SID-2 data are only used for the measurements in cirrus. Data presented from other cloud types in this study had particle concentrations that were high enough to result in coincidence issues in the SID-2 data. The OAPs used are a Two-Dimensional-Cloud (2D-C) probe and two versions of the Cloud Imaging Probe (the CIP-15 and CIP-100). A description of these instruments and the processing of the data is given in Cotton et al. (2013). The maximum particle size in the direction parallel to the photodiode array was used for $D$. All of the OAP instruments had modified tips fitted to the probe arms following the design of Korolev et al. (2011, $2013 \mathrm{~b}$ ) in order to minimise the impact of shattered ice particle fragments entering the probe sample volume. In order to combine the data from the different instruments, a composite PSD is derived following the methodology described in Cotton et al. (2013).

\section{Results}

The data presented in this study were obtained during the PIKNMIX field experiment in January and February 2012. The FAAM BAe-146 aircraft was based at Prestwick airport in Scotland, and the scientific flights were primarily performed over oceanic regions to the north and west of the UK. A wide range of cloud physics sorties were flown during the campaign, which provides us with an opportunity to compare the performance of the different ice water content measurement techniques in a variety of cloud regimes.

\subsection{Stratocumulus}

Figure 1 shows example data from a run in the upper part of a mixed-phase low-level stratocumulus cloud deck that formed during a cold-air outbreak episode to the north of Scotland (flight B668, 23 January 2012). The cloud top temperature was $-11^{\circ} \mathrm{C}$ and predominantly consisted of supercooled liquid droplets. Peak cloud top liquid water contents of around $0.5 \mathrm{~g} \mathrm{~m}^{-3}$ and typical cloud droplet number concentrations of $40 \mathrm{~cm}^{-3}$ were measured. Ice particles were observed in small regions of the cloud layer and ice hydrometeors were observed to precipitate to the sea surface.

The $q_{\mathrm{t}}$ measured along the flight track with the total water probe and the $q_{\mathrm{v}}$ measured with the two WVSS-II instruments are shown in Fig. 1a. It is evident that the different WVSS-II instruments respond differently in the liquid cloud layer, with the instrument on the Rosemount inlet having markedly higher values. This is thought to be due to cloud droplets evaporating in the Rosemount inlet due to adiabatic heating of the air, which subsequently leads to an artificial enhancement in the $q_{\mathrm{v}}$ measurement (Vance et al., 2014). It is clear from the case presented that close to complete evaporation of the cloud droplets must have occurred as the Rosemount WVSS-II data are similar to the 

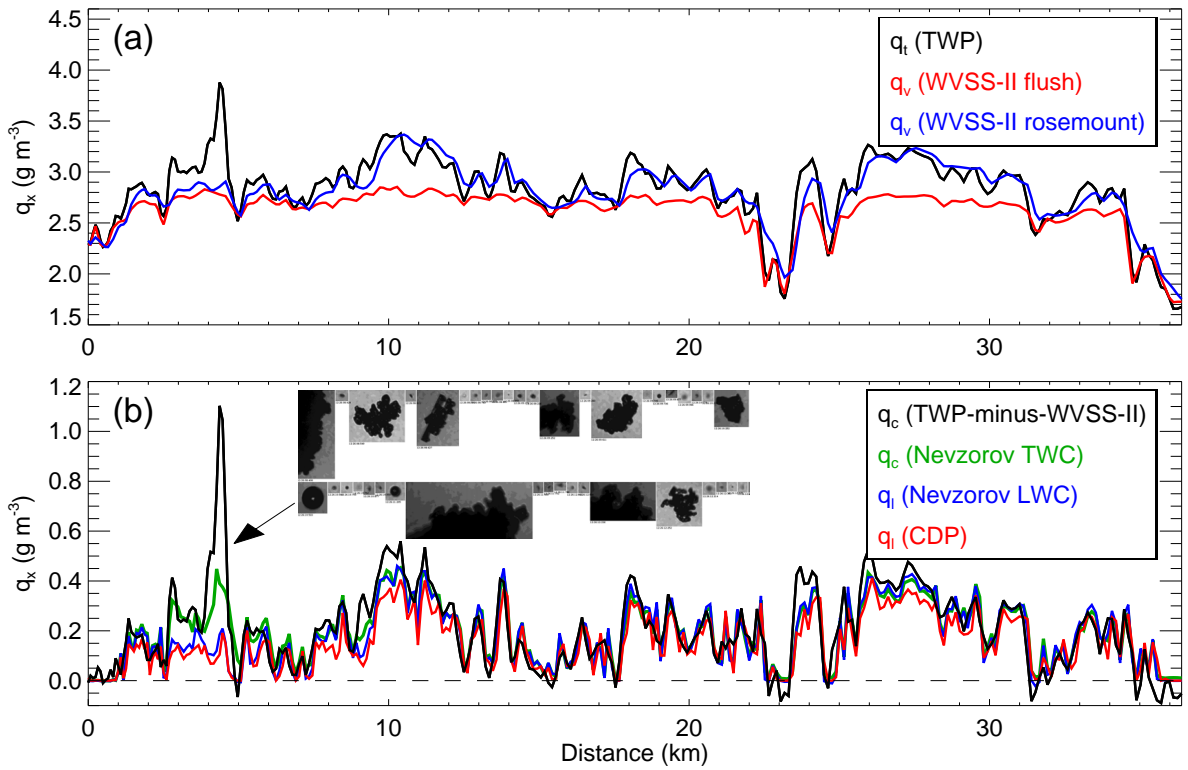

Figure 1. Example data from flight B668 in stratocumulus cloud at a temperature of $-9{ }^{\circ} \mathrm{C}$. Panel (a) shows the measured $q_{\mathrm{t}}$ from the total water probe, $q_{\mathrm{v}}$ from both WVSS-II instruments. Panel (b) shows the measured $q_{\mathrm{c}}$ from the Nevzorov probe and from the TWP-minusWVSS-II (flush inlet) method. Also included are measurements of liquid water content from the CDP and Nevzorov $q_{1}$ sensor. Example CPI imagery in a region containing ice particles is also shown.

$q_{\mathrm{t}}$ probe measurement. A slower-response chilled-mirror hygrometer (General Eastern 1011B) gives good agreement with the flush-mounted WVSS-II measurement (not shown). We therefore utilise the flush-mounted WVSS-II data for cases where liquid water is present.

The various bulk water content measurements are shown in Fig. 1b. $q_{1}$ data from the integration of the CDP size distribution measurement (assuming liquid water drops) is also shown. The CDP measures particles with diameters between 2 and $50 \mu \mathrm{m}$, which covers the size range of the liquid cloud drops. For the majority of the flight track, the cloud is predominantly composed of liquid water and all of the methods are in good agreement. However, both the Nevzorov $q_{\mathrm{c}}$ sensor and the TWP-minus-WVSS-II methods show enhancements in the water content between 2.5 and $5 \mathrm{~km}$ along the flight track when compared to the instruments that only measure $q_{1}$. Examination of particle imagery from a SPEC Inc. Cloud Particle Imager (CPI) Version 1.5 probe shows the occurrence of mixed-phase conditions in this region of the cloud. An example image in Fig. 1b shows that aggregates of irregular crystals and large supercooled drizzle drops are present. Whilst there is good agreement between the two $q_{\mathrm{c}}$ measurements between 2.5 and $3.5 \mathrm{~km}$ along the track, the TWP-minus-WVSS-II method gives peak values approaching $1.1 \mathrm{~g} \mathrm{~m}^{-3}$ between 3.5 and $5 \mathrm{~km}$, whereas the Nevzorov $q_{\mathrm{c}}$ measurement peaks at a lower value of $0.45 \mathrm{~g} \mathrm{~m}^{-3}$. The difference could result from the sample volume of the total water probe $\left(7.9 \mathrm{~L} \mathrm{~s}^{-1}\right.$ at $\left.100 \mathrm{~m} \mathrm{~s}^{-1}\right)$ and Nevzorov cone $\left(5 \mathrm{~L} \mathrm{~s}^{-1}\right.$ at $\left.100 \mathrm{~m} \mathrm{~s}^{-1}\right)$ being insufficient to obtain a statistically significant sample of the largest ice particles and drizzle drops that are present. Occasional large particles that are sampled could, therefore, result in a spike in the data. The fact that the instruments are not collocated may also contribute to the difference. Both techniques, however, are able to identify mixed-phase conditions when compared to a bulk measurement of $q_{1}$.

\subsection{Convective clouds}

Data from aircraft penetrations made through mixed-phase cumulus clouds over the ocean to the north-west of the UK (flight B667, 22 January 2012) are shown in Figs. 2 and 3. Cloud bases were at an altitude of about $600 \mathrm{~m}$ and a temperature of $1{ }^{\circ} \mathrm{C}$. The tops of the largest convective elements reached an altitude of about $4.4 \mathrm{~km}$ and a temperature of $-24^{\circ} \mathrm{C}$. Surface precipitation rates of 1 to $4 \mathrm{~mm} \mathrm{~h}^{-1}$ were typically observed in the region of the aircraft operations from a nearby Met Office operational weather radar.

Figure 2a shows the total water probe and WVSS-II data from an aircraft flight leg that intercepted several cumulus clouds at a temperature of $-14.4{ }^{\circ} \mathrm{C}$. In clear air the two instruments track each other and then diverge when in cloud. It is evident that the $q_{\mathrm{v}}$ in the cloud is typically higher than the surrounding environment as moister air from below is transported in the cloud updraught. Evidence of enhanced humidity halos are seen around some of the cloud edges, for example at $40 \mathrm{~km}$ along the flight track where the $q_{\mathrm{v}}$ in clear air is similar to the adjacent in-cloud values.

The corresponding bulk water content measurements are shown in Fig. 2b. The TWP-minus-WVSS-II method shows 

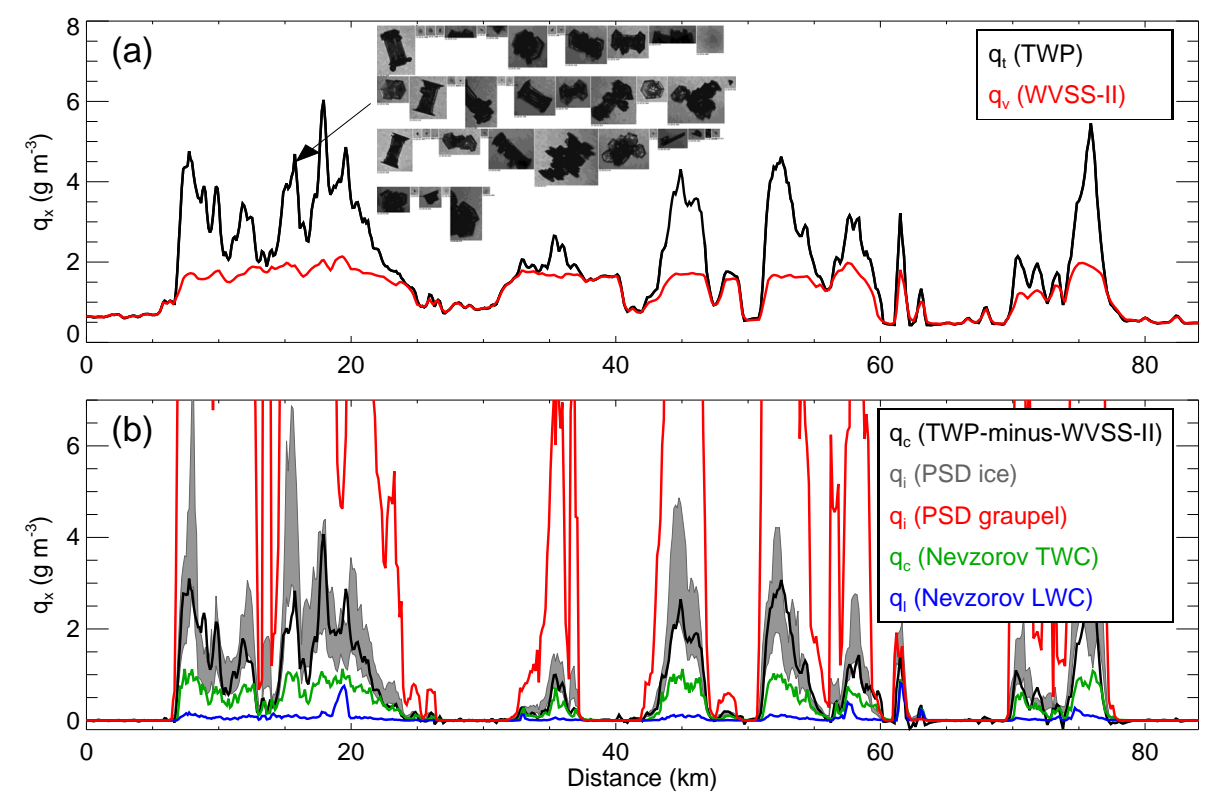

Figure 2. Example data from cumulus cloud penetrations made during flight B667 at a temperature of $-14.4{ }^{\circ} \mathrm{C}$. Panel (a) shows the measured $q_{\mathrm{t}}$ from the total water probe and $q_{\mathrm{v}}$ from the WVSS-II instrument. Example CPI imagery is also shown. Panel (b) shows the $q_{\mathrm{c}}$ measured by the Nevzorov probe and from the TWP-minus-WVSS-II method. Also included are measurements of the liquid water content from the Nevzorov $q_{1}$ sensor. The grey shading shows a range of $q_{\mathrm{i}}$ estimates from integration of the measured PSD using a selection of $M-D$ relations for ice, and the red line shows an estimate of $q_{\mathrm{i}}$ using a $M-D$ relation for graupel (see Table 1).

peak $q_{\mathrm{c}}$ values of 2 to $4 \mathrm{~g} \mathrm{~m}^{-3}$ in the clouds sampled. The Nevzorov probes measurement of $q_{\mathrm{c}}$, however, shows much lower peak values of about $1 \mathrm{~g} \mathrm{~m}^{-3}$. This is likely to result from the power supplied to the Nevzorov hot-wire cone being insufficient to melt and then evaporate all of the captured ice particles. This has been observed in wind tunnel tests and manifests itself in a pooling of melted water inside the cone. This liquid water is then subsequently swept out of the cone into the airflow (Korolev et al., 2013a). Examination of the power supplied to the Nevzorov cone during these cloud penetrations confirms that it has reached an upper limit (not shown). Also shown in Fig. 2b, with a grey band, are estimates of $q_{\mathrm{i}}$ from the integration of the composite PSD using a range of $M-D$ relations for pristine ice crystals and aggregates. These habits are representative of the typical particles found during these cloud penetrations as shown with the example particle imagery from the CPI. This grey band generally spans the measurements made with the TWP-minusWVSS-II method and provides additional evidence for the underestimation in $q_{\mathrm{c}}$ from the Nevzorov instrument. Another estimate of $q_{\mathrm{i}}$ from the PSD, but using an $M-D$ relation for graupel, gives much higher values than the bulk measurements, illustrating the need to make an a priori assumption on the particle type when integrating the PSD data. Finally, data from the Nevzorov $q_{1}$ sensor shows the presence of supercooled liquid within the convective clouds, with values of $q_{1}$ that approach $1 \mathrm{~g} \mathrm{~m}^{-3}$, e.g. at 19 and $61 \mathrm{~km}$ along the aircraft track.
A second example from an aircraft run that intercepted precipitation at cloud base is shown in Fig. 3. In contrast to the more pristine ice particles measured higher up in the clouds (Fig. 2), the leading edge of the precipitation cell at $50 \mathrm{~km}$ along the run was dominated by heavily rimed/graupel-type particles as shown in the CPI imagery. Integration of the composite PSD with the graupel $M-D$ relation gives much better agreement with the bulk $q_{\mathrm{c}}$ measurement from the TWP-minus-WVSS-II method than if the ice $M-D$ relations are used. Again the Nevzorov probe significantly underestimates $q_{\mathrm{c}}$ in this precipitation cell, and an examination of the power supplied to the Nevzorov cone in this time period shows that it has again reached an upper limit (not shown). There is much better agreement between the Nevzorov $q_{\mathrm{c}}$ sensor and the TWP-minus-WVSS-II methods in the second precipitation cell at about $107 \mathrm{~km}$ along the flight track, where the $q_{\mathrm{c}}$ was less than $0.5 \mathrm{~g} \mathrm{~m}^{-3}$ and where heavily rimed particles were not observed in the particle imagery. It is interesting to note that the TWP-minus-WVSS-II method is able to capture this well, even though the surrounding $q_{\mathrm{v}}$ variations are about a factor of 3-4 larger than the peak $q_{\mathrm{c}}$.

\subsection{Cirrus}

Data are presented from measurements made in midlatitude stratiform cirrus located ahead of a surface warm frontal feature to the north-west of the UK (flight B672, 30 January 2012). The aircraft descended in a race-track pattern 

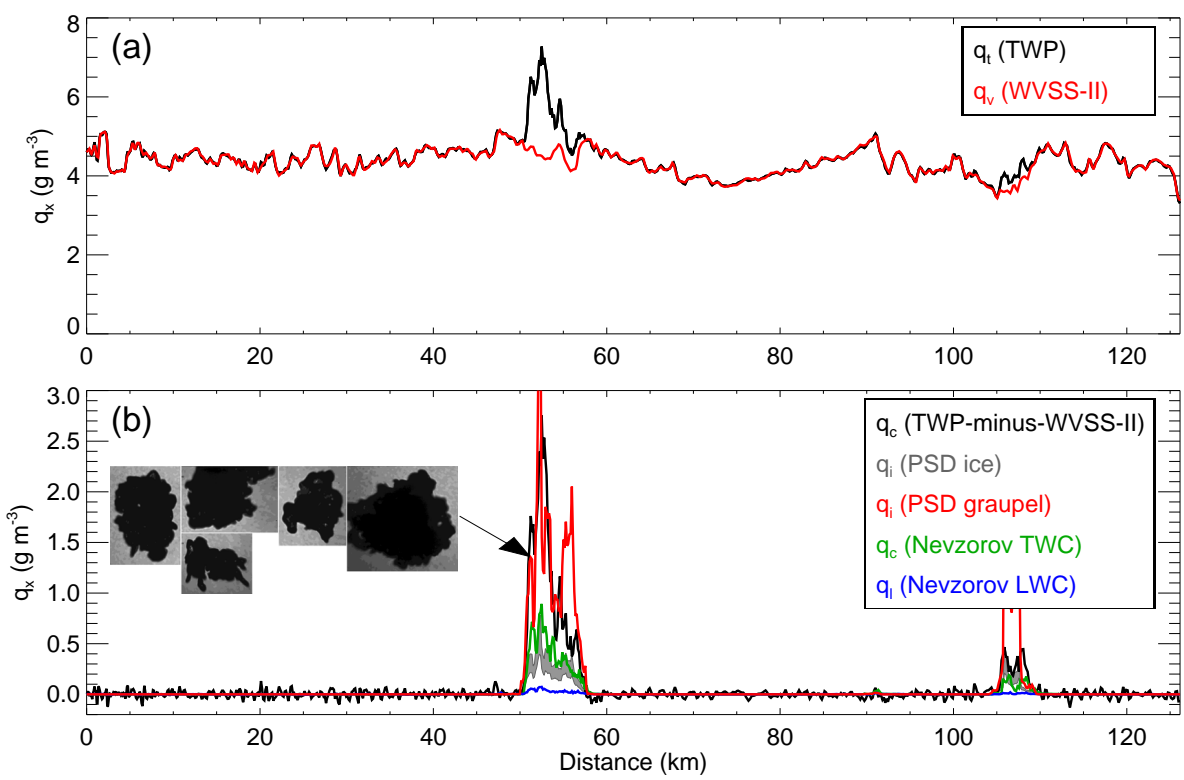

Figure 3. As Fig. 2 but showing measurements in precipitation at cloud base made during flight $\mathrm{B} 667$ at a temperature of $-1.3^{\circ} \mathrm{C}$.

through the cloud layer from the cloud top region (temperature of $-48^{\circ} \mathrm{C}$ ) to near the cloud base (temperature of $-9^{\circ} \mathrm{C}$ ) whilst drifting with the horizontal wind. The average descent rate of the aircraft was chosen to be comparable to the typical mass-weighted mean fall speed of the ice particles (approximately $0.5 \mathrm{~m} \mathrm{~s}^{-1}$ ). The flight pattern attempted to target a region of enhanced $q_{\mathrm{i}}$ and follow this population of ice particles as they fell through the more widespread cirrus cloud.

Figure 4 shows an illustrative subset of this data taken in the middle of the cloud layer between temperatures of -27 and $-19^{\circ} \mathrm{C}$. The $q_{\mathrm{v}}$ measured with the WVSS-II is observed to increase by $0.54 \mathrm{~g} \mathrm{~m}^{-3}$ during this period, which is about a factor of 3 higher than the corresponding peak $q_{\mathrm{i}}$ in the cloud. The WVSS-II with the Rosemount inlet is used because it has been shown to perform better than the standard flush inlet at the drier humidities encountered at the top of the cloud layer $\left(q_{\mathrm{v}}\right.$ of $\left.0.05 \mathrm{~g} \mathrm{~m}^{-3}\right)$ (Vance et al., 2014). It is clear from Fig. 4a that in regions of low $q_{\mathrm{i}}$ the $q_{\mathrm{t}}$ measured with the total water probe tracks the general increase in $q_{\mathrm{v}}$ during the descent. The $q_{\mathrm{i}}$ estimated from the $5 \mathrm{~s}$ time-averaged PSDs is shown with a grey band in Fig. $4 \mathrm{~b}$. This band spans the variability that results from the integration of the PSD with the different $M-D$ relations for ice particles described in Sect. 2.4. The example imagery from the CPI shows that pristine ice particles and aggregates thereof are dominant. Also shown are data from the different bulk estimates of $q_{\mathrm{i}}$. For all of the bulk ice water content methods, a $5 \mathrm{~s}$ boxcar smoothing has been applied to the data for comparison. The gaps in the CVI data are where the instrument was zeroed. The enhanced $q_{\mathrm{i}}$ regions correspond to times when the aircraft intercepted the ice particle fall streak as it descended through the cloud layer. It is evident that all of the techniques are in general agreement and capture the same structure seen in the time series of $q_{\mathrm{i}}$.

Figure 5 compares the Nevzorov $q_{\mathrm{c}}$ sensors bulk $q_{\mathrm{i}}$ measurement (there was no liquid water present and so $q_{\mathrm{c}}=q_{\mathrm{i}}$ ) against the other techniques from the complete $3.5 \mathrm{~h}$ racetrack descent through the cirrus cloud. Each filled circle represents the median value and the vertical bars the 25 th to 75 th percentile range from $10 \mathrm{~min}$ of flight data. Above about $0.02 \mathrm{~g} \mathrm{~m}^{-3}$ the TWP-minus-WVSS-II method is in good agreement with the Nevzorov data. Below this value there is a rapid drop-off in the $q_{\mathrm{i}}$ derived from the total water probe and WVSS-II. The data also become much noisier at these lower $q_{\mathrm{i}}$ values as is evident from the larger vertical bars representing the 25th to 75th percentiles of the data. A large component of this represents scatter in the data around the zero- $q_{\mathrm{i}}$ line that results from deriving the $q_{\mathrm{i}}$ from the difference between the two instruments. This scatter can also be seen in the time series data presented in Fig. 4. It is also similar to the residual found between the two instruments in clear air as shown in Appendix B. We therefore find that the TWP-minus-WVSS-II method should only be used for $q_{\mathrm{i}}$ values in excess of $0.02 \mathrm{~g} \mathrm{~m}^{-3}$. In contrast, the CVI data are in fairly good agreement with the Nevzorov measurement for $q_{\mathrm{i}}$ values in excess of $0.008 \mathrm{~g} \mathrm{~m}^{-3}$. There is a tendency for the CVI to give higher values than the Nevzorov probe at $q_{\mathrm{i}}$ values in excess of $0.03 \mathrm{~g} \mathrm{~m}^{-3}$, but the two techniques generally give agreement to within $50 \%$. Further examination of the data at lower ice water content values is given below. Finally a range of $q_{\mathrm{i}}$ estimates from the integration of the PSD using a selection of ice $M-D$ relations from the literature is shown with the grey shading. These all tend 

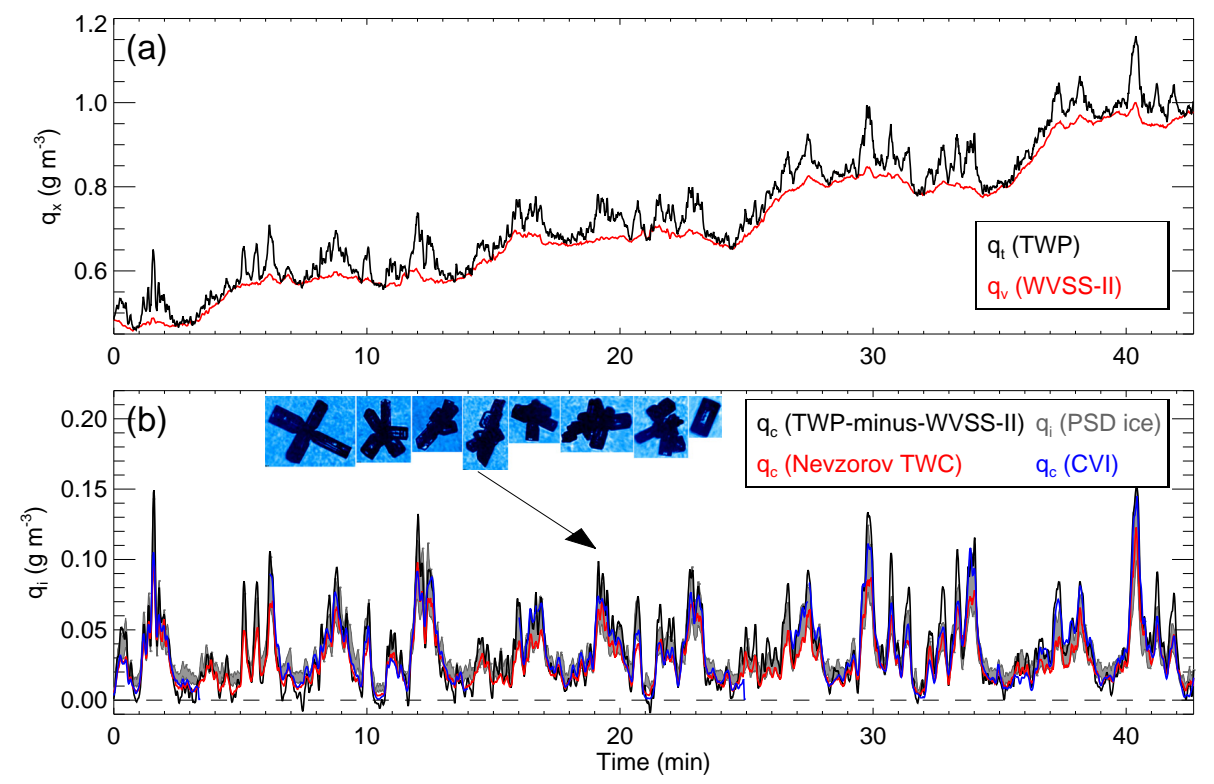

Figure 4. Example data from a race-track descent made in cirrus cloud during flight $\mathrm{B} 672$ between temperatures of -27 and $-19^{\circ} \mathrm{C}$. Panel (a) shows the measured $q_{\mathrm{t}}$ from the total water probe and $q_{\mathrm{v}}$ from the WVSS-II instrument. Panel (b) shows the $q_{\mathrm{i}}$ from the Nevzorov $q_{\mathrm{c}}$ sensor, data from the TWP-minus-WVSS-II method and data from the CVI. The grey shading shows a range of $q_{\mathrm{i}}$ estimates from the integration of the measured PSD using a selection of $M-D$ relations for ice (see Table 1). Example CPI imagery is also shown.

to give good agreement with the Nevzorov data at $q_{\mathrm{i}}$ values in excess of about $0.02 \mathrm{~g} \mathrm{~m}^{-3}$. Below this value the PSD gives significantly higher values than the bulk measurements.

This is examined further in Fig. 6b which shows the ratio of the Nevzorov $q_{\mathrm{i}}$ to the PSD $q_{\mathrm{i}}$ estimate as a function of temperature. Again the grey shading shows the variability from the selection of ice $M-D$ relations. It is evident that good agreement is seen at temperatures warmer than about $-25^{\circ} \mathrm{C}$. At colder temperatures higher up in the cloud layer the integrated PSD overestimates the $q_{\mathrm{i}}$. This suggests that an altitude-dependent $M-D$ relation is required to match the bulk measurements of $q_{\mathrm{i}}$ throughout the depth of the cirrus, which we parametrise as a function of temperature. Following Heymsfield et al. (2007), we derive a temperature-dependent value of the $a$ coefficient in the $M-D$ relation whilst assuming a constant value of the $b$ coefficient. For each circuit of the race-track descent through the cloud layer, we fix $b=2.1$ and vary $a$ to find the best agreement with the Nevzorov data. The best-fit value of $a$ is shown in black in Fig. 6a as a function of temperature. There is a linear dependence of $a$ for $-48<T<-16^{\circ} \mathrm{C}$ given by $a=C_{0}+C_{1} T$, where the constants are $C_{0}=0.0901$ and $C_{1}=0.001449$. At temperatures warmer than $-16^{\circ} \mathrm{C}$ no obvious trend in $a$ is observed, and we fix $a$ at a value of 0.0669 . We also derive a second $M-D$ relation that fixes $a=0.05$ and varies $b$ to find the best agreement with the Nevzorov data. This is shown in red in Fig. 6b. Again there is a linear dependence for temperatures colder than $-16^{\circ} \mathrm{C}$ that is given by $b=C_{2}+C_{3} T$, where $C_{2}=1.9868$ and $C_{3}=-0.004059$.

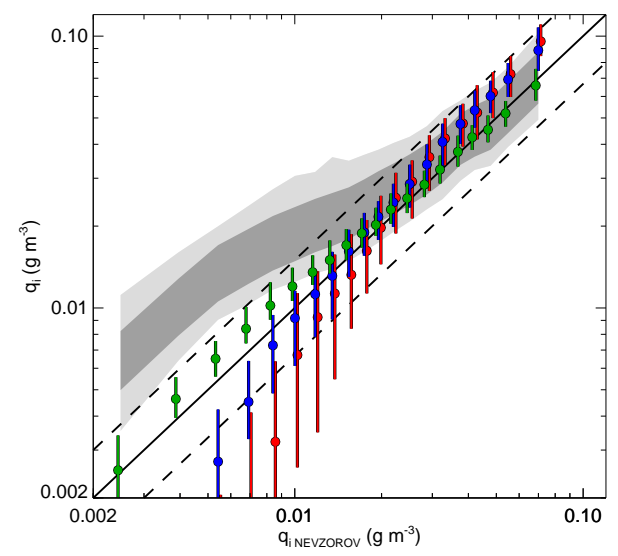

Figure 5. A comparison of Nevzorov data against the other $q_{\mathrm{i}}$ measurement techniques. The TWP-minus-WVSS-II method is shown in red, the CVI in blue and the integration of the PSD using the temperature-dependent relation $M=0.05 D^{b(T)}$ from this study in green (see Table 1). The data are from flight B762 in cirrus cloud between temperatures of -48 and $-9^{\circ} \mathrm{C}$. Each filled circle represents the median value and the vertical bars the 25 th to 75 th percentile range from 10 min of flight data. The dark/light grey shading spans the extremities of the median/interquartile range when integrating the PSD using a selection of other temperature-invariant $M-D$ relations for ice (see Table 1). The solid line is the $1: 1$ line. The dashed lines represent agreement to within a factor of 1.5.

At temperatures warmer than $-16^{\circ} \mathrm{C}$ we fix $b$ at 2.05 . Applying either of these temperature-dependent $M-D$ relations to the PSD data results in much better agreement with the 

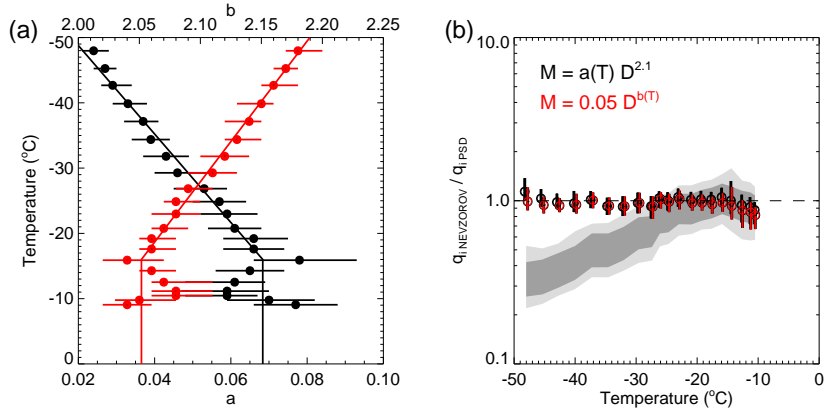

Figure 6. Panel (a) shows two temperature-dependent $M-D$ relations for flight B672. The filled circles are the median and the vertical bars the interquartile range from each $5 \mathrm{~s}$ PSD in different temperature ranges. The black data vary the $a$ coefficient and fix $b=2.1$. The red data vary the $b$ coefficient and fix $a=0.05$. The solid lines are a fit to the data (see Table 1). Panel (b) shows the ratio of the $q_{\mathrm{i}}$ measured with the Nevzorov probe to that from the integration of the PSD using the two temperature-dependent $M-D$ relations (same colours as in panel a). Each circle represents the median value and the vertical bars the interquartile range from $10 \mathrm{~min}$ of flight data. The dark/light grey shading spans the extremities of the median/interquartile range when integrating the PSD using a selection of temperature-invariant $M-D$ relations for ice from the literature (see Table 1).

Nevzorov bulk measurement. This is shown as a function of both $q_{\mathrm{i}}$ in Fig. 5 (green symbols) and temperature in Fig. 6b (black/red symbols). We note that one could choose different fixed $a$ and $b$ coefficients and derive equally valid temperature-dependent $M-D$ relations which also result in a good fit to the data. The objective here is to illustrate that the application of temperature-invariant $M-D$ relations to the PSD is unable to reproduce the observed bulk measurement of $q_{\mathrm{i}}$.

In addition to the data from B672, a comparison of the CVI and Nevzorov probe measurement of $q_{\mathrm{i}}$ from three other flights in midlatitude cirrus clouds are shown in Fig. 7. The typical $q_{\mathrm{i}}$ values measured during these additional flights are lower than the TWP-minus-WVSS-II method can resolve, and so those data are not presented. Flight B669 (24 January 2012) was another race-track descent through a $3.6 \mathrm{~km}$ deep stratiform cirrus layer, although the peak $q_{\mathrm{i}}$ measured was a factor of 10 lower than on flight B672. Flight B671 (29 January 2012) made some measurements within a cloud band associated with a warm front to the north-west of the UK. Flight B673 (1 February 2012) made measurements in a thin cirrus layer over Scotland ahead of a surface cold frontal feature. There is generally good agreement (within a factor of 2) between the $1 \mathrm{~Hz} \mathrm{CVI}$ and Nevzorov data across all of the cirrus measurements for $q_{\mathrm{i}}>0.008 \mathrm{~g} \mathrm{~m}^{-3}$. For lower ice water contents, the CVI tends to underestimate $q_{\mathrm{i}}$ due to the lower detectable limit of the hygrometer in the CVI (see Appendix C).

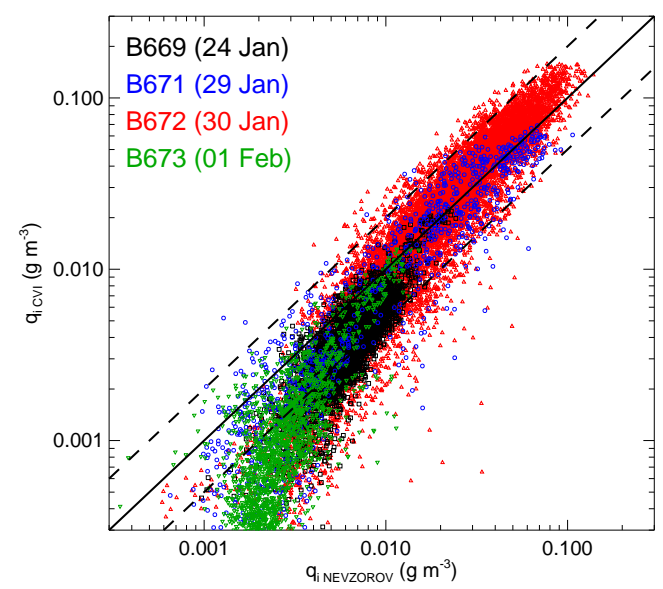

Figure 7. A comparison of $1 \mathrm{~Hz}$ Nevzorov data and CVI $q_{\mathrm{i}}$ measurements in midlatitude cirrus clouds. The solid line is the $1: 1$ line, and the dashed lines represent a factor-of- 2 difference between the measurements.

\section{Conclusions}

We present a comparison of ice water content data using a variety of measurement techniques on the FAAM BAe-146 research aircraft. These include evaporative techniques using a CVI and a TWP-minus-WVSS-II water vapour method, a hot-wire technique using a Nevzorov $q_{\mathrm{c}}$ sensor and techniques based on integration of the measured PSD. Examples are shown from research flights that sampled a variety of cloud types during the PIKNMIX field campaign. The CVI data are only available for the cirrus measurements because the unheated inlet was subject to icing issues in mixed-phase conditions.

The TWP-minus-WVSS-II technique is the only method that was capable of measuring the high bulk water contents (several $\mathrm{g} \mathrm{m}^{-3}$ ) found in the convective clouds on flight B667. Data from the Nevzorov $q_{\mathrm{c}}$ sensor appeared to saturate at a value of about $1 \mathrm{~g} \mathrm{~m}^{-3}$ due to insufficient electrical power being supplied to the cone to enable it to melt and then evaporate all of the captured ice particles, something that has been observed in wind tunnel tests (Korolev et al., 2013a). Whilst the integration of the PSD with an appropriate $M$ $D$ relation did result in $q_{\text {i }}$ estimates that were comparable to the TWP-minus-WVSS-II method, an a priori assumption of particle habit was required. For the convective clouds on flight B667, supercooled liquid drops, pristine ice particles and larger, more heavily rimed graupel-type particles were present in different regions of the cloud, and it was critical to use the appropriate $M-D$ relation to estimate $q_{\mathrm{i}}$ from the PSD. For cold convective cloud studies it is therefore highly desirable to have a high bulk water content measurement capability, such as the TWP-minus-WVSS-II technique. 
In the lower-ice-water-content environments typically found in cirrus clouds, we develop a new parametrisation of the baseline drift for the Nevzorov $q_{\mathrm{c}}$ sensor in order to achieve a sensitivity of $\pm 0.002 \mathrm{~g} \mathrm{~m}^{-3}$ in $q_{\mathrm{c}}$ (see Appendix A). All of the bulk measurement techniques capture the same structure in $q_{\mathrm{i}}$ within the cirrus and typically agree to within a factor of 2 for $q_{\mathrm{i}}>0.02 \mathrm{~g} \mathrm{~m}^{-3}$. Below this value, the data from the TWP-minus-WVSS-II method are unreliable as the $q_{\mathrm{i}}$ is comparable to the residual difference between data from the two instruments in clear air (see Appendix B). The Nevzorov and CVI data are in good agreement for $q_{\mathrm{i}}>0.008 \mathrm{~g} \mathrm{~m}^{-3}$, below which the CVI tends to underestimate $q_{\mathrm{i}}$ due to the fundamentally lower detectable limit of the hygrometer (see Appendix C). Integration of the PSD with a variety of temperature-invariant $M-D$ relations for ice from the literature gave good agreement with the Nevzorov measurement for $q_{\mathrm{i}}>0.02 \mathrm{~g} \mathrm{~m}^{-3}$. At lower ice water contents the PSD estimate of $q_{\mathrm{i}}$ was significantly overestimated. In order to obtain better agreement between the PSD and bulk measurements of $q_{\mathrm{i}}$ for flight B672, we derive two different temperature-dependent $M-D$ relations. These either fix the $a$ or the $b$ coefficient in the $M-D$ relation and allow the other to vary with temperature. Both result in a much better match of the $q_{\mathrm{i}}$ derived from the PSD across the range of ice water contents and temperature measured during flight B672. We note that a temperature dependence of the $M_{-}$ $D$ relation has been observed in stratiform cirrus clouds by other investigators (Heymsfield et al., 2007, 2010; Schmitt and Heymsfield, 2010). This highlights the requirement to make an a priori assumption about the $M-D$ relation when integrating the PSD data to estimate the $q_{\mathrm{i}}$. In order to test these assumptions, a bulk measurement technique that is capable of measuring the range of ice water contents typically found in cirrus clouds with sufficient, accuracy such as the Nevzorov probe, is required.

In boundary layer stratocumulus clouds we show an example where both the Nevzorov $q_{\mathrm{c}}$ sensor and the TWP-minusWVSS-II techniques are able to detect mixed-phase conditions when compared to additional liquid water content measurements. In parts of the mixed-phase region of the cloud there were discrepancies between the two instruments measurement of $q_{\mathrm{c}}$ which may be attributable to the sample volumes of the total water probe and the Nevzorov cone being insufficient to obtain a statistically significant sample of the largest ice particles and drizzle drops. Further examination of data from additional flights is required in future studies to better understand this difference. 


\section{Appendix A: Nevzorov baseline}

The detailed operation of the Nevzorov probe is described in Korolev et al. (1998). Briefly, the reference sensor power with heat loss due to forced convection is given by

$P_{\mathrm{r}}=\alpha_{\mathrm{r}}\left(T_{\mathrm{r}}-T_{\mathrm{a}}\right)$,

where $\alpha_{\mathrm{r}}$ is the bulk convective heat transfer coefficient and is a function of the Nusselt number, thermal conductivity of air and of the actual sensor shape. $T_{\mathrm{r}}$ is the temperature of the reference sensor, and $T_{\mathrm{a}}$ is the air temperature.

The collector sensor power additionally includes the power due to evaporation of the cloud water:

$P_{\mathrm{c}}=\alpha_{\mathrm{c}}\left(T_{\mathrm{c}}-T_{\mathrm{a}}\right)+q_{\mathrm{c}} L^{*} S U$,

where $\alpha_{\mathrm{c}}$ is the bulk convective heat transfer coefficient for the collector sensor, $T_{\mathrm{c}}$ is the temperature of the collector sensor, $S$ is the collector sample area, $L^{*}$ is the energy required to melt and then evaporate the condensed water, $U$ is the airspeed and $q_{\mathrm{c}}$ is the cloud water content.

Since the reference and collector sensors are maintained at the same temperature $\left(T_{\mathrm{r}}=T_{\mathrm{c}}\right)$, the water content is given by

$q_{\mathrm{c}}=\frac{\left(P_{\mathrm{c}}-K P_{\mathrm{r}}\right)}{U S L^{*}}$

where $K$ is the ratio

$K=\frac{P_{\mathrm{c}, \text { conv }}}{P_{\mathrm{r}, \text { conv }}}=\frac{\alpha_{\mathrm{c}}}{\alpha_{\mathrm{r}}}$.

$P_{\mathrm{c}, \text { conv }}$ is the collector power, and $P_{\mathrm{r} \text {, conv }}$ is the reference power, dissipated while in cloud-free air and containing only the forced convective heat loss. The sensitivity of $K$ to changes in temperature, pressure and airspeed is much lower than the bulk convective heat transfer coefficients, but to achieve the desired probe accuracy the $K$ coefficient is normally determined after significant changes of airspeed and altitude (setting $K$ while in cloud-free air is equivalent to zeroing the baseline).

However, when the aircraft is in cloud for an extended period of time with the aircraft attitude and environmental conditions changing, the change in $K$ limits the sensitivity to $\sim 0.01 \mathrm{~g} \mathrm{~m}^{-3}$. Korolev et al. (1998) show the baseline drift caused by the $K$ sensitivity and conclude that changes in airspeed and altitude are key parameters. In order to determine how best to parametrise $K$, a series of aircraft manoeuvres were carried out. During science measurements the aircraft normally flies at a fixed indicated airspeed (IAS). This means that as the altitude increases and both the pressure and temperature decrease, the true airspeed (TAS) also changes.

The requirement is to parametrise $K$ as a linear function of known variables and to determine the validity range. A set of flight manoeuvres were, therefore, performed in order to separate the effects of airspeed, pressure and temperature. Each
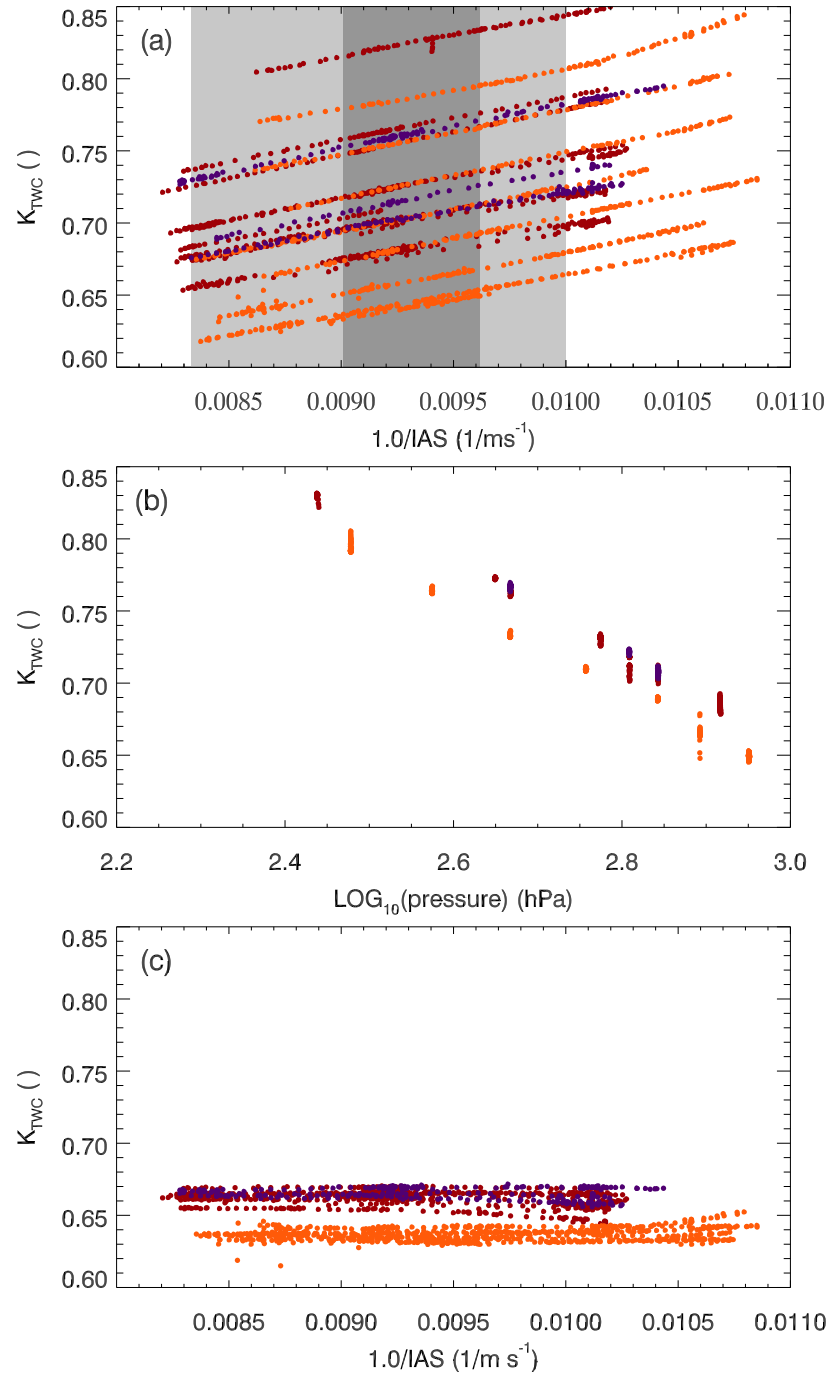

Figure A1. The change in cloud-free collector to reference sensor power during a number of straight and level runs. Panel (a) shows the effect of airspeed (each line of symbols are for one run at constant pressure, temperature and altitude, with only the airspeed varying). Panel (b) shows the response to pressure after an airspeed correction has been applied; panel (c) shows the response after additional pressure correction. The three different colours represent different cones.

set was carried out while in cloud-free air in straight and level flight such that the temperature and pressure were largely invariant (covering around 20 flights). During the manoeuvres the aircraft flew at up to five different values of IAS. These legs were then performed at a variety of altitudes. Figure A1a shows the variation of $K$ as a function of the inverse of IAS for each of these sets of straight and level runs ( $K$ did not vary linearly with TAS). The dark grey band represents the typical range of airspeed during numerous flights while attempting to fly at science speed. The light grey band also includes transits and climbs while at best range speed, etc., 

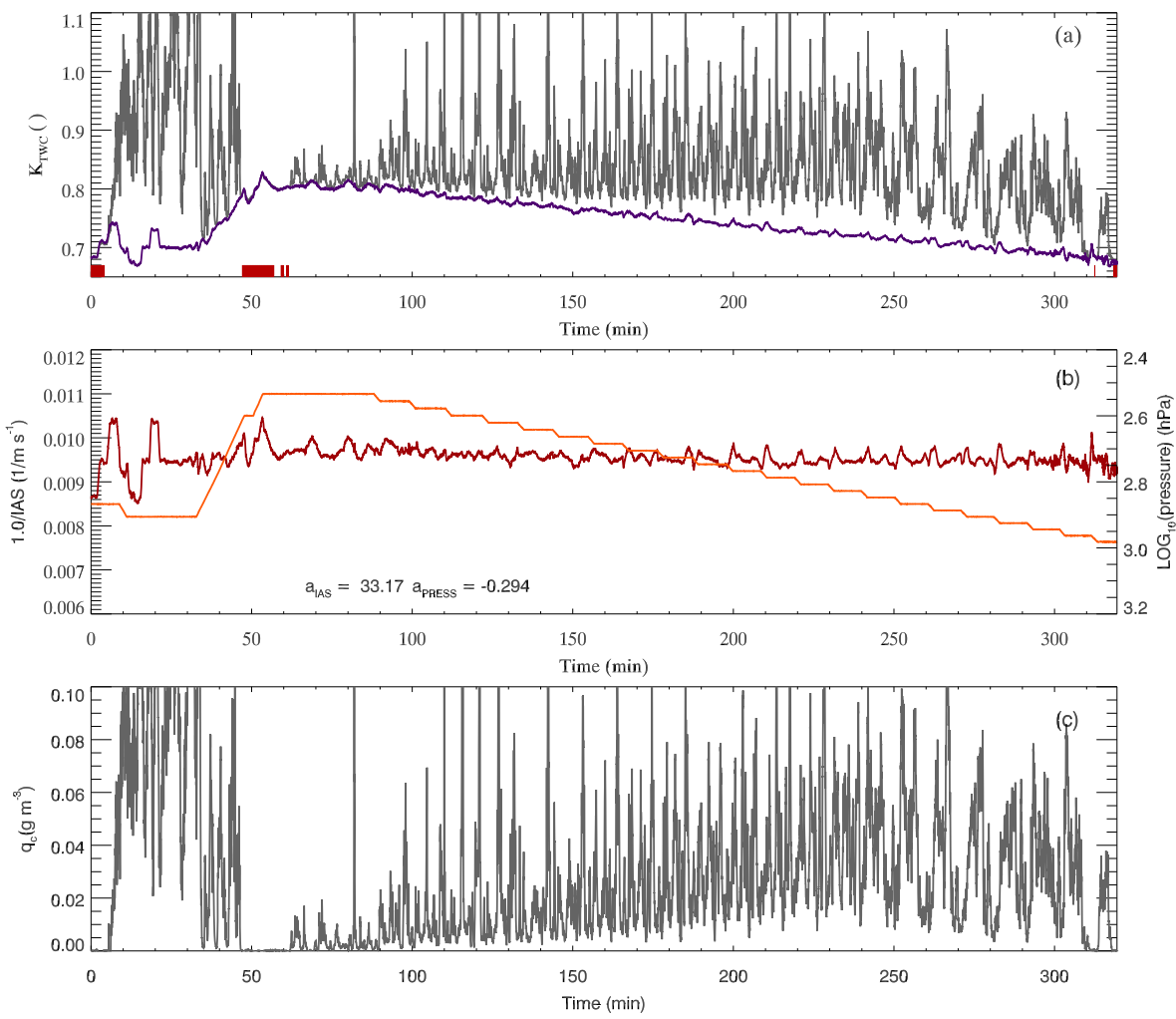

Figure A2. Data from flight B672 which was mostly in cloud. In panel (a) the grey line is the measured ratio of collector to reference power, and the purple line is the parametrised $K$. The red bars represent the times when in cloud-free air. Panel (b) shows the variation of $1 / V_{\mathrm{IAS}}$ (the red line) and $\mathrm{LOG}_{10}(P)$ (the orange line) during the flight. Panel (c) shows the baseline-corrected $q_{\mathrm{c}}$ using the best-fit parametrised $K$.

and, over this range, the gradients are similar so that the airspeed dependence on $K$ is

$\Delta K=30.0 \Delta\left(1 / V_{\mathrm{IAS}}\right)$,

where $V_{\text {IAS }}$ has units $\mathrm{ms}^{-1}$.

It is straightforward to remove the effect of airspeed, leaving the altitude or temperature dependence to be investigated more easily, and Fig. A1b shows the variation of $K$ as a function of pressure after the $V_{\text {IAS }}$ correction. The pressure dependence on $K$ is

$\Delta K=-0.29 \Delta \mathrm{LOG}_{10}(P)$,

where the pressure $P$ has units hPa. Figure A1c shows $K$ after the airspeed and pressure corrections have been applied. The different colours represent different cones which are not all identical. The two parameters $1 / V_{\text {IAS }}$ and $\mathrm{LOG}_{10}(P)$ capture most of the variation of $K$, typically \pm 0.01 which corresponds to a change in condensed-water content of \pm 0.0025 $\mathrm{g} \mathrm{m}^{-3}$. Valid for all flights, the change in $K$ is

$\Delta K=a_{\mathrm{IAS}} \Delta\left(1 / V_{\mathrm{IAS}}\right)+a_{P} \Delta \mathrm{LOG}_{10}(P)$,

where $a_{\mathrm{IAS}}=30.0$ and $a_{P}=-0.29$ are the parametrisation coefficients.
To try and achieve better sensitivity, the coefficients can be determined on a flight-by-flight basis using all of the cloudfree data. Figure A2a-c show data for flight B672, which, over a period of over $3 \mathrm{~h}$, slowly descended from 28000 to $6000 \mathrm{ft}$, always in cloud. In panel a, the small red bars indicate the cloud-free sections, and the grey line is the ratio of collector to reference power, which includes bulk water evaporation. Panel $b$ shows the variation of airspeed and pressure during the same time period. The parametrisation coefficients $a_{\mathrm{IAS}}$ and $a_{P}$ are determined by numerical minimisation and the calculated $K$ is shown by the purple line in panel a. The parametrised $K$ then gives the $q_{\mathrm{c}}$ shown in panel c. The structure in $q_{\mathrm{c}}$ is because this flight targeted a region of cirrus where fall streaks were prevalent. Without knowledge of how $K$ varies while in cloud, the baseline of $q_{\mathrm{c}}$ in panel c would potentially have errors up to $0.01 \mathrm{~g} \mathrm{~m}^{-3}$ (for example, at $250 \mathrm{~min}$ the baseline might be set at $0.01 \mathrm{~g} \mathrm{~m}^{-3}$ ).

The question is how accurate the parametrised $K$ during extended in-cloud periods is. Figure A3 shows the variation in $K$ for two flights which were all in cloud-free air and where various speed changes and other aircraft manoeuvres were carried out. The best-fit parametrised $K$ follows the actual measured $K$ remarkably well. Inset into each panel are histograms of the difference, 

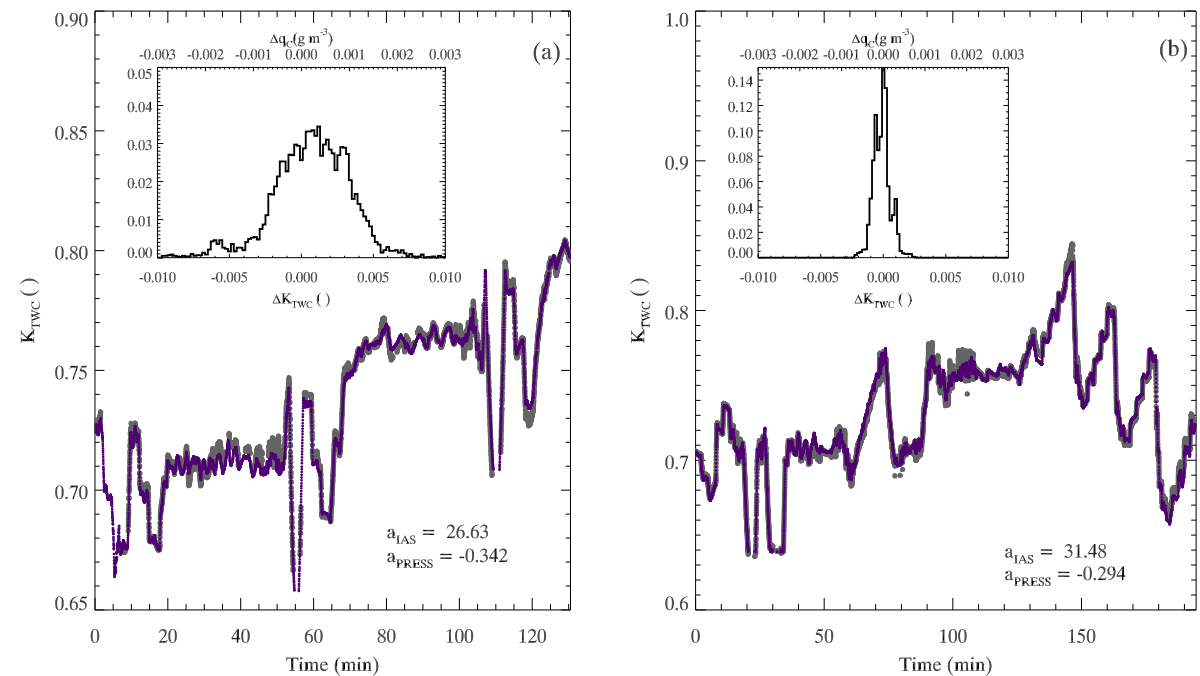

Figure A3. Data from cloud-free flights B666 (a) and B785 (b). The grey line is the measured ratio of collector to reference power, and the purple line is the parametrised $K$. Inset are histograms of the difference between these variables. The effect of airspeed changes on $K$ are clearly seen as steps in panel (b) between times 130 and 200 min.

$\frac{P_{\mathrm{c}}}{P_{\mathrm{r}}}-\left(a_{\mathrm{IAS}} \Delta\left(1 / V_{\mathrm{IAS}}\right)+a_{P} \Delta \mathrm{LOG}_{10}(P)\right)$

with the equivalent change in $q_{\mathrm{c}}$ on each top axis. The variation on $q_{\mathrm{c}}$ ranges from \pm 0.0005 to $\pm 0.0015 \mathrm{~g} \mathrm{~m}^{-3}$ over $2-$ $3 \mathrm{~h}$.

\section{Appendix B: Calibration of the total water probe}

The output voltage from the Lyman- $\alpha$ absorption hygrometer in the total water probe is a linear function of the water vapour density at the sample pressure and temperature after corrections for the absorption of oxygen have been applied (Nicholls et al., 1990; Brown, 1993). In this study we calibrate the total water probe in clear-air segments of a flight against the $q_{\mathrm{v}}$ measurement from the WVSS-II. Furthermore, we account for the baseline drift of the total water probe during a flight by numerical minimisation of the clear-air difference between the total water probe and WVSS-II. During this baseline procedure the total water probe data are smoothed to be comparable to the $0.4 \mathrm{~Hz}$ data rate of the WVSS-II. Whilst the near-infrared tunable diode laser absorption hygrometer used in the WVSS-II is much more stable over long periods of time and therefore subject to less drift than the total water probe (Vance et al., 2014), the baseline procedure will also capture any such occurrence.

Figure B1 compares the calibrated total water probe data against the WVSS-II measurement from $2.5 \mathrm{~h}$ of clear-air data during flight B667. This includes data from a series of profiles and from clear-air segments made during runs that intercepted convective clouds between an altitude of $20 \mathrm{~m}$ to

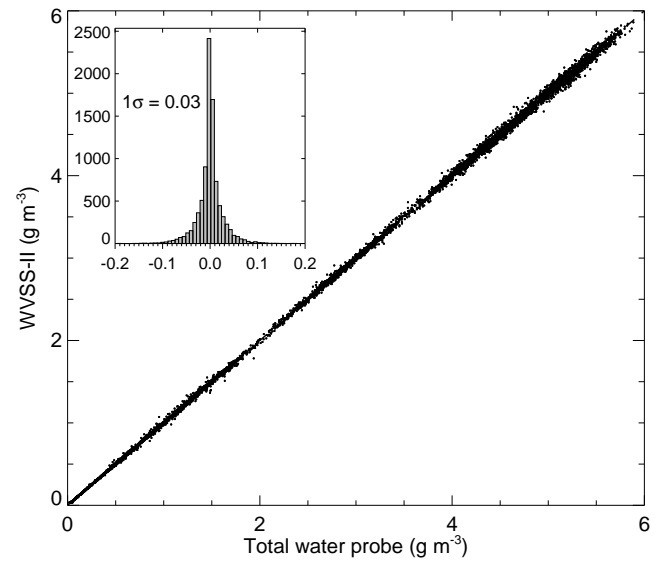

Figure B1. Water vapour content from the total water probe and flush-mounted WVSS-II in clear-air conditions during flight B667. The dashed line is the $1: 1$ line. The inset panel shows a histogram of the difference between the total water probe and WVSS-II measurement.

$7 \mathrm{~km}$, sampling a $q_{\mathrm{v}}$ range of 0.03 to $5.9 \mathrm{~g} \mathrm{~m}^{-3}$. The residual between the two instruments is shown with the inset histogram and has a $1 \sigma$ value of $0.03 \mathrm{~g} \mathrm{~m}^{-3}$. The other flights analysed in this paper have $1 \sigma$ values of $0.02 \mathrm{~g} \mathrm{~m}^{-3}$ from $3.5 \mathrm{~h}$ of clear-air data during flight B668 and $0.01 \mathrm{~g} \mathrm{~m}^{-3}$ from $1 \mathrm{~h}$ of clear-air data during flight B672.

\section{Appendix C: CVI operational details and processing}

This appendix gives a detailed description of the measurement of $q_{\mathrm{c}}$ using the CVI inlet on the FAAM BAe-146, including the production of a dry carrier air stream, the 
estimation of the Lyman- $\alpha$ hygrometer baseline and the subsequent calculations. The limitations of the system are then presented. The effects of the blunt tip geometry and lower and upper cut size of the CVI are considered and sources of error are discussed.

Cloud particles with sufficient inertia to pass the stagnation plane within the tip are introduced into a carrier air stream where they evaporate. This dry, particle-free carrier air stream is generated onboard the aircraft from cabin air using a high-efficiency particle filter and two Drierite desiccant filled canisters. The dew point of the air produced is typically less than $-40^{\circ} \mathrm{C}$. This air is heated to $50^{\circ} \mathrm{C}$ as it passes into the porous section of the CVI inlet. The sample air is also heated to $50^{\circ} \mathrm{C}$ to aid evaporation of cloud particles, until the point where the sample passes through the aircraft skin into the cabin. The sample then begins to cool towards the ambient cabin temperature. The temperature within the CVI plumbing and hygrometer system is above $25^{\circ} \mathrm{C}$ and usually closer to $30^{\circ} \mathrm{C}$. This dry carrier air is also passed at ambient cabin temperature to the reference channel of the hygrometer. We account for a time lag in the CVI measurements due to the time required to deliver the sampled air from the inlet to the hygrometer by cross-correlation with the Nevzorov measurements. This time lag is approximately $8 \mathrm{~s}$ and is in agreement with an estimated value calculated from the measured flow velocities within the CVI plumbing.

\section{C1 Calculating condensed-water content}

The Lyman- $\alpha$ hygrometer responds to the optical depth of absorbing material between the lamp and the detector. As condensed water is evaporated into the sample air stream, there is a difference between the optical depth of water vapour in the sample and reference channels. The logarithm of the ratio between the voltages from the sample channel, $V_{\mathrm{Ly}_{I}}$, and the reference channel, $V_{\mathrm{Ly}_{I_{0}}}$, can be related to the ambient condensed-water content, $q_{\mathrm{c}}$, by taking account of the enhancement factor of the inlet, $\mathrm{EF}_{\mathrm{cvi}}$, environmental conditions and the dilution flow rate. The $q_{\mathrm{c}}\left(\mathrm{g} \mathrm{m}^{-3}\right)$ is derived as a function of the absorptance measured by the Lyman- $\alpha$ hygrometer, $A_{\text {Ly }}$, by

$q_{\mathrm{c}}=\frac{\left(K_{\mathrm{Ly}} K_{\mathrm{env}} A_{\mathrm{Ly}}\right)}{\mathrm{EF}_{\mathrm{cvi}}}$,

where

$A_{\mathrm{Ly}}=\log _{10}\left[\frac{\left(V_{\mathrm{Ly}_{I}} / V_{\mathrm{Ly}_{I_{0}}}\right)}{\mathrm{DR}_{\mathrm{Ly}}}\right]$.

The enhancement factor, $\mathrm{EF}_{\mathrm{cvi}}$, is the factor by which the cloud particle number concentration is increased for those particles that are selected by the CVI inlet (Noone et al., 1993). It is calculated in this study from the ratio between the volume of air swept out by the tip and the mass flow of air into which the cloud particles are introduced within the CVI. The typical values range from $\mathrm{EF}_{\mathrm{cvi}}=30$ at an altitude of $8 \mathrm{~km}$ to $\mathrm{EF}_{\mathrm{cvi}} \approx 10$ in the boundary layer. The variable $K_{\mathrm{Ly}}=\left(10^{-6} \times M_{\mathrm{H}_{2} \mathrm{O}}\right) /\left(N_{A} \times \sigma_{\mathrm{H}_{2} \mathrm{O}} \times l_{\text {path }}\right)$, where the sample chamber path length $l_{\text {path }}=3.04 \mathrm{~cm}$, the absorption cross section of the water molecule $\sigma_{\mathrm{H}_{2} \mathrm{O}}=1.6 \times 10^{-17} \mathrm{~m}^{-2}$ at a $\lambda_{\mathrm{Ly}}=121.567 \mathrm{~nm}$ (Vatsa and Volpp, 2001), $N_{A}$ is Avogadro's number and $M_{\mathrm{H}_{2} \mathrm{O}}$ is the molar mass of the water molecule. $K_{\text {env }}$ accounts for the ratio between dilution flow and the sample flow in the hygrometer and the increase in air density within the CVI as compared to ambient conditions. $\mathrm{DR}_{\mathrm{Ly}}$ is defined below.

\section{C2 Dry-ratio baseline and limitations}

Improved measurement of $q_{\mathrm{c}}$ is possible if the time dependence of the performance drift of the hygrometer is well characterised. Dry-ratio zero-checks are performed frequently, typically more than 10 times during a $5 \mathrm{~h}$ flight. During a zero-check the dry carrier air is diverted through both the sample and reference channels of the instrument and the "dry ratio" between the two detector outputs is recorded. Manual intervention determines when the flow has stabilised following the switch over to carrier air and determines that both chambers are sufficiently dry. These manually located dryratio spot checks are linearly interpolated throughout a flight. The dry signal, $\mathrm{DR}_{\mathrm{Ly}}$, in Eq. (C2) can then be removed. It is not possible to collect data whilst a zero-check is being undertaken.

The upper and lower limits of measurable $q_{\mathrm{c}}$ are determined by the instrument configuration and local operating conditions, such as sample flow rates, dilution factor within the hygrometer, true airspeed (i.e. enhancement factor) and pressure. The gain of the detector amplifiers is adjusted preflight to allow for maximum dynamic range. Dilution flow to the hygrometer can be adjusted in flight to give dilution factors on the sample flow between 10 and $50 \%$. The upper limit of humidity (i.e. optical depth within the sample chamber) is determined by the lowest possible output of the sample detector and amplifier system. A minimum value of $200 \mathrm{mV}$ with a safety margin of $50 \%$ is applied to account for uncertainties in the National Instrument amplification and digital to analogue Converter hardware.

The lower limit is determined by the minimum detection threshold for absorptance of the hygrometer. Zuber and Witt (1987) estimate that the minimum value of absorptance that this type of hygrometer can detect is $A_{\mathrm{Ly}}=0.1$. Figure C1 shows $q_{\mathrm{i}}$ measured by the Nevzorov $q_{\mathrm{c}}$ sensor against that measured by the CVI for four cirrus flights, shown by black symbols. The data are then screened for three values of the lower detection limit of absorptance: $A_{\mathrm{Ly}}=0.05,0.10,0.15$. The lower limit of detection for the hygrometer in this configuration appears to be $0.10 \leq A_{\mathrm{Ly}} \leq 0.15$ as this is where the comparison between $q_{\mathrm{i}}$ measured by the Nevzorov and CVI techniques is linear. This analysis gives confidence in 


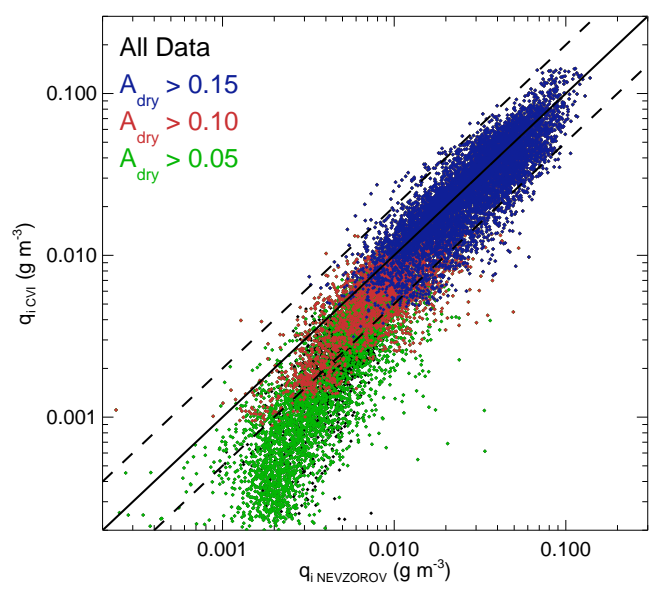

Figure C1. A comparison of $1 \mathrm{~Hz}$ Nevzorov data and CVI $q_{\mathrm{i}}$ measurements taking the minimum detectable absorptance of the Lyman- $\alpha$ hygrometer into account. The solid line is the $1: 1$ line and the dashed lines represent a factor-of- 2 difference between the measurements. See text for details.

the ability of the Nevzorov at these low masses as there is a physical basis for the departure between CVI and Nevzorov.

The determination of the dry ratio leads to one of the major uncertainties within the system. The value of the dry ratio typically increases by about $5 \%$ throughout a flight. The exact rate of change of the dry ratio between zero-checks is unknown and so data are rejected if the ratio between the measured signals at any time is less than 0.015 greater than the estimated dry ratio at that time. Hysteresis is sometimes observed on CVI $q_{\mathrm{c}}$ measurements when sampling high water mass concentrations (Heymsfield et al., 2007). This was not observed on the cirrus sampling flights presented but is likely to be a problem if this CVI is used in future to sample cumulus clouds. Data are removed when the diagnostic parameters indicating lamp temperature and lamp light output are outside operating limits.

The determination of part of the sample flow that passes through a critical orifice is uncertain at higher altitudes as the orifice becomes subcritical due to a low-pressure drop across it. It is possible to recover some of the data by using other flow sensors, but data become unusable when the pressure within the CVI is below $375 \mathrm{mb}$. Due to uncertainty in the measured flow rates used to determine the flow balance of the inlet, there are times when it is not possible to be sure that the inlet is operating with an excess flow out of the tip. The tip geometry and the variability of the flow measurements are used to determine and screen for data where $L_{\mathrm{cvi}}$ is below the minimum length that is physically possible, with a small error margin. Data are also rejected from times when noise and spikes on the measured flow signals would give an unknown value for the water vapour concentration calculation.

\section{C3 Cut size and blunt tip limitations}

The CVI inlet was operated with the minimum achievable cut size. The lower cut size, $D_{50}$, of a CVI inlet is well described by simple geometric theory, e.g. Noone et al. (1988), as confirmed by more detailed modelling studies, e.g. Lin and Heintzenberg (1995). The blunt tip found on this inlet leads to some uncertainty on the exact determination of $L_{\mathrm{cvi}}$, the distance between the upper stream stagnation plane and the stagnation plane within the porous section. For the flights presented here the cut size is calculated with an upstream flow distortion constant $G_{\mathrm{r}}=2.0$ (Anderson et al., 1993). The blunt tip used here is expected to negatively affect the cut size performance of the inlet to some extent. The blunt tip may also affect the cut sharpness, the rate at which the collection efficiency rises to 1.0 above the $D_{50}$ value. Laucks and Twohy (1998) find that $100 \%$ efficiency for droplet selection with a sharp tip may not be reached until $\approx 100 \mu \mathrm{m}$. The effect is likely to be somewhat worse for a blunt tip. However, given the range of ice crystals encountered during the cirrus flights, especially in terms of the mass distribution, the comparison between the CVI and other instruments should be relatively independent of particle habit and size. The inlet used on the BAe-146 has a shorter porous section than the one considered by Laucks and Twohy (1998), and this may actually act to increase the cut sharpness. The blunt tip will lead to some uncertainty in the determination of $q_{\mathrm{c}}$ mass when a significant part of the mass distribution is contained in sizes at or just larger than the cut size of the inlet.

Clouds particles that are still larger than $50 \mu \mathrm{m}$ when they reach a $90^{\circ}$ bend in the sample pipe prior to passing through the aircraft fuselage are likely to impact the pipe wall. Residual condensation nuclei may remain stuck to the walls and be lost, but as the pipework is heated to $50^{\circ} \mathrm{C}$ the moisture will readily evaporate and be sampled. The temporal resolution of the $q_{\mathrm{c}}$ measurement may be reduced as this moisture takes a finite amount of time to evaporate (Ström et al., 1994). 
Acknowledgements. We would like to thank all of the crew and personnel involved in the PIKNMIX campaign. The BAe-146 research aircraft was operated by Directflight Ltd/Avalon and managed by the Facility for Airborne Atmospheric Measurements (FAAM), which is jointly funded by the Met Office and Natural Environment Research Council (NERC). The CPI data were provided by Ian Crawford, University of Manchester, Centre for Atmospheric Science, School of Earth, Atmospheric and Environmental Science. The CPI instrument is supported by the NERC National Centre for Atmospheric Science.

Edited by: S. Malinowski

\section{References}

Anderson, T. L., Charslon, R. J., and Covert, D. S.: Calibration of a counterflow virtual impactor at aerodynamic diameters from 1 to $15 \mu \mathrm{m}$, Aerosol Sci. Tech., 19, 317-329, 1993.

Baran, A. J., Bodas-Salcedo, A., Cotton, R. J., and Lee, C.: Simulating the equivalent radar reflectivity of cirrus at $94 \mathrm{GHz}$ using an ensemble model of cirrus ice crystals: a test of the Met Office global numerical weather prediction model, Q. J. Roy. Meteorol. Soc., 137, 1547-1560, 2011.

Baumgardner, D., Brenguier, J. L., Bucholtz, A., Coe, H., DeMott, P., Garrett, T. J., Gayet, J. F., Hermann, M., Heymsfield, A., Korolev, A., Kramer, M., Petzold, A., Strapp, W., Pliewskiw, P., Taylor, J., Twohy, C., Wendisch, M., Bachalo, W., and Chuang, P.: Airborne instruments to measure atmospheric aerosol particels, clouds and radiation: a cook's tour of mature and emerging technology, Atmos. Res., 102, 10-29, 2011.

Brown, P. R. A.: Measurement of the ice water content in cirrus using an evaporative technique, J. Atmos. Ocean. Tech., 10, 579590, 1993.

Brown, P. R. A. and Francis, P. N.: Improved measurement of the ice water content in cirrus using a total-water probe, J. Atmos. Ocean. Tech., 12, 410-414, 1995.

Cotton, R. J., Field, P. R., Ulanowski, Z., Kaye, P. H., Hirst, E., Greenaway, R. S., Crawford, I., Crosier, J., and Dorsey, J.: The effective density of small ice particles obtained from in situ aircraft observations of mid-latitude cirrus, Q. J. Roy. Meteorol. Soc., 139, 1923-1934, 2013.

Davis, S. M., Avallone, L. M., Weinstock, E. M., Twohy, C. H., Smith, J. B., and Kok, G. L.: Comparisons of in situ measurements of cirrus cloud ice water content, J. Geophys. Res., 112, D10212, doi:10.1029/2006JD008214, 2007.

Heymsfield, A. J. and Kajikawa, M.: An improved approach to calculating terminal valocities of plate-like crystals and graupel, J. Atmos. Sci., 44, 1088-1099, 1987.

Heymsfield, A. J., Bansemer, A., and Twohy, C. H.: Refinements to ice particle mass dimensional and terminal velocity relationships for ice clouds. Part I: Temperature dependence, J. Atmos. Sci., 64, 1047-1067, 2007.

Heymsfield, A. J., Schmitt, C., and Bansemer, A.: Improved representation of ice-particle masses based on observations in natural clouds, J. Atmos. Sci., 67, 3303-3318, 2010.

Korolev, A. V., Strapp, J. W., Isaac, G. A., and Nevzorov, A. N.: The Nevzorov airborne hot-wire LWC-TWC probe: principle of operation and performance characteristics, J. Atmos. Ocean. Tech., 15, 1495-1510, 1998.
Korolev, A. V., Emery, E. F., Strapp, J. W., Cober, S. G., Isaac, G. A., Wasey, M., and Marcotte, D.: Small ice particles in tropospheric clouds: fact or artifact? Airborne icing instrumentation evaluation experiment, B. Am. Meteorol. Soc., 92, 967-973, 2011.

Korolev, A. V., Strapp, J. W., Isaac, G. A., and Emery, E.: Improved airborne hot-wire measurements of ice water content in clouds, J. Atmos. Ocean. Tech., 30, 2121-2131, 2013a.

Korolev, A. V., Emery, E., and Creelman, K.: Modification and tests of particle probe tips to mitigate effects of ice shattering, J. Atmos. Ocean. Tech., 30, 690-708, 2013b.

Laucks, M. L. and Twohy, C. H.: Size dependant collection efficiency of an airborne counterflow virtual impactor, Aerosol Sci. Tech., 28, 40-61, 1998.

Lin, H. and Heintzenberg, J.: A theoretical study of the counterflow virtual impactor, J. Aerosol Sci., 26, 903-914, 1995.

Mitchell, D. L., Zhang, R., and Pitter, R. L.: Mass dimensional relationships for ice particles and the influence of riming on snowfall rates, J. Atmos. Sci., 29, 153-163, 1990.

Mitchell, D. L., D’Entremont, R. P., and Lawson, R. P.: Inferring cirrus size distributions through satellite remote sensing and microphysical databases, J. Atmos. Sci., 67, 1106-1125, 2010.

Nicholls, S., Leighton, J., and Barker, R.: A new fast response instrument for measuring total water content from aircraft, J. Atmos. Ocean. Tech., 7, 706-718, 1990.

Noone, K. B., Noone, K. J., Heintzenberg, J., Ström, J., and Ogren, J. A.: In situ observations of cirrus cloud microphysical properties using the counterflow virtual impactor, J. Atmos. Ocean. Tech., 10, 294-303, 1993.

Noone, K. J., Ogren, J. A., Heintzenberg, J., Charlson, R. J., and Covert, D. S.: Design and calibration of a counterflow virtual impactor for sampling of atmospheric fog and cloud droplets, Aerosol Sci. Tech., 8, 235-244, 1988.

Öström, E., Noone, K. J., and Pockalny, K.: Cloud droplet residual particle microphysics in marine stratocumulus clouds observed during the Monterey Area Ship Track Experiment, J. Aerosol Sci., 57, 2671-2683, 2000.

Schmitt, C. G. and Heymsfield, A. J.: The dimensional characteristics of ice crystal aggregates from fractal geometry, J. Atmos. Sci., 67, 1605-1616, 2010.

Ström, J., Heintzenberg, J., Noone, K. J., Noone, K. B., Ogren, J. A., Albers, F., and Quante, M.: Small crystals in cirriform clouds: a case study of residue size distribution, cloud water content and related cloud properties, Atmos. Res., 32, 125-141, 1994.

Vance, A. K., Abel, S. J., Cotton, R. J., and Woolley, A. M.: Performance of WVSS-II hygrometers on the FAAM Research Aircraft, Atmos. Meas. Tech. Discuss., 7, 8643-8667, doi:10.5194/amtd-7-8643-2014, 2014.

Vatsa, R. K. and Volpp, H.-R.: Absorption cross sections for some atmospherically important molecules at the $\mathrm{H}$ atom Lyman$\alpha$ wavelength (121.567 nm), Chem. Phys. Lett., 340, 289-295, 2001.

Zuber, A. and Witt, G.: Optical hygrometer using differential absorption of hydrogen Lyman- $\alpha$ radiation, Appl. Optics, 26, 3083-3089, 1987. 